\title{
Plugging and Its Stability Evaluation for the Ore Pass in the Nonempty Condition Based on Controllable Grouting of Cement- Sodium Silicate Grout
}

\author{
Ye Yuan (iD, ${ }^{1,2}$ Dengpan Qiao $\mathbb{D}^{1},{ }^{1}$ and Shibo $\mathrm{Yu}^{2,3}$ \\ ${ }^{1}$ Faculty of Land Resources Engineering, Kunming University of Science and Technology, Kunming, Yunnan 650093, China \\ ${ }^{2}$ BGRIMM Technology Group, Beijing 100160, China \\ ${ }^{3}$ Civil and Resource Engineering School, University of Science and Technology Beijing, Beijing 100083, China
}

Correspondence should be addressed to Dengpan Qiao; 13015401@qq.com

Received 24 November 2020; Revised 6 January 2021; Accepted 12 January 2021; Published 3 February 2021

Academic Editor: Feng Xiong

Copyright ( 92021 Ye Yuan et al. This is an open access article distributed under the Creative Commons Attribution License, which permits unrestricted use, distribution, and reproduction in any medium, provided the original work is properly cited.

\begin{abstract}
Aimed at the problem to plug the main ore pass with the large collapse at Xingshan Iron Mine, the viscosity-time test and the heap perfusion test of cement-silicate grout in a loose rock mass are carried out. The relationship between the vertical diffusion distance of cement-silicate grout and setting time of grout is studied, and research results are applied to the design of plugging engineering of the main ore pass in $-330 \mathrm{~m}$. Based on the numerical simulation of the plugging structure and the long-term stress monitoring of the cable sensors, the stability of the plugging structure itself and the control for the movement of shafts nearby are comprehensively evaluated. The test results show that for a specific loose rock mass, the vertical diffusion distance of cement-silicate grout in the loose rock mass is a power function of grout setting time. Based on the design concept to plug the main ore pass with the large collapse using artificially constructed "bite-bonded arch," the plugging design and construction procedures are proposed. A numerical model and long-term monitoring of cable stress show that the plugging structure is stable and has an obvious effect on the control movement of abutment shafts.
\end{abstract}

\section{Introduction}

The main ore pass as an important passage for ore transfer is critical to maintaining normal production of all mines. The main ore pass is affected by ore impact and long-term wear of the wall; generally, there are a series of large collapses in the local areas of the main ore pass $[1,2]$. Due to the production needs, the main ore pass is generally near by the main shaft and auxiliary shaft, and the collapses have created a direct threat to the stability of the nearby shafts. Therefore, the main ore pass management and continued utilization have become a prominent problem faced by many large mines. Among them, the use of the lower section to plug the severely collapsed upper section has become the preferred strategy for most main ore passes, but under the normal condition, this option faces the instability in the vicinity caused by emptying the upper section of the main ore pas. Therefore, it is the best choice to plug the main ore pass in the fully filled state, but it is still necessary to overcome several problems which include the controllable grouting and its filling fullness.

Domestically and internationally, there are few studies on the large collapse of the main ore pass, mainly focusing on the mechanism and countermeasures of the overhanging arch $[2,3]$, the stability analysis of the ore pass, and the grouting reinforcement [1, 4]. Li et al. [5], Shi et al. [6], and Qin et al. [7] are mainly centering on the microscomic fracture of the laboratory test and the fracture due to water on the collapse of rock mass. A set of equations is proposed for the description of the distribution of the vertical suspended sediment diffusion coefficient for engineering purposes which improves the correlation with a set of measured diffusion coefficient values by Kim and Jang [8]. Li et al. [9] use large direct shear tests to investigate influences of shape properties (symmetry and smoothness) of gravel particles. Hadjigeorgiou and Lessard [10, 11], Vo et al. [12], and 


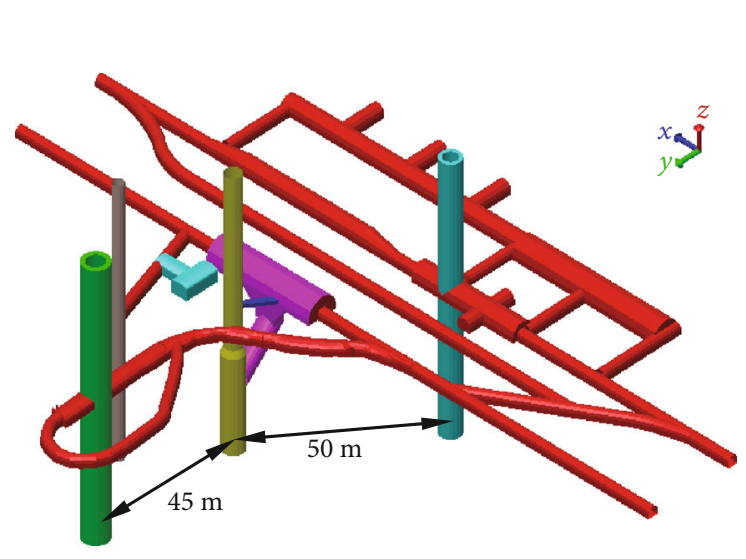

(a) Layout of shaft and drift near the main ore pass

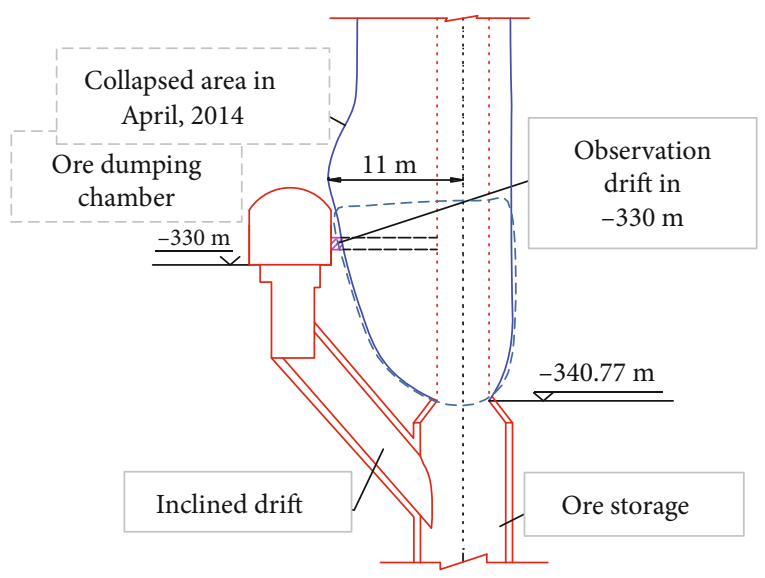

(b) Collapse area in $-330 \mathrm{~m}$ of the main ore pass

Figure 1: The status of the main ore pass.

Szwedzicki [13] mainly studied the mechanism of an overhanging arch in the ore pass and its influence factors and proposed some solutions. Kuang and Song [14] and Esmaieli et al. [15] use numerical simulation to evaluate and analyze the stability of the ore pass and its group with the large collapse. Li et al. [16] conduct an exploratory study on the plugging of the large collapsed ore pass at Xincheng Gold Mine by using the grouting reinforcement for the loose rock mass, but the method has several shortcomings of low efficiency and large difficulty in the construction. Li et al. [17-19] suggested that the performance of the grouting material be tested before industrial production, and the yield criterion of the rock and the weakening effect of water should be analyzed. Wang et al. [20] and Meng et al. [21] analyzed the application prospects of cement-water glass controllable grouting from energy policy and new material physical property prediction methods, and they have good engineering application prospects.

Aimed at the problem to plug the main ore pass with the large collapse at Xingshan Iron Mine, the viscosity-time test of cement-silicate grout and the heap perfusion test of cement-silicate grout in a loose rock mass are carried out. The relationship between the vertical diffusion distance of cement-silicate grout and the setting time of grout is studied, and the research results are applied to the design of the plugging engineering of the main ore pass in $-330 \mathrm{~m}$ at Xingshan Iron Mine. Based on the numerical simulation of the plugging structure and the long-term stress monitoring of the cable sensors, the stability of the plugging structure itself and the effect for the movement of the main shaft and auxiliary shaft nearby are comprehensively evaluated.

\section{Engineering Situation}

2.1. The Status of the Main Ore Pass. Xingshan Iron Mine which is attached to Shougang Mining Company is an underground large-scale iron ore mine with an annual output of 3.2 million tons. As the only main ore pass in the mine, it is responsible for the entire mine transfer and becomes the throat of this mine. The main ore pass is $45 \mathrm{~m}$ away from the main shaft and $50 \mathrm{~m}$ away from the auxiliary shaft, as shown in Figure 1(a). Since December 2010, the main ore pass has appeared to have different damage in the different sections of the ore pass including steel plate grinding, slipping, and large-scale collapses in the wall, as shown in Figure 1(b). At the level from $-330 \mathrm{~m}$ to $-180 \mathrm{~m}$, there are as many as 12 large-scale collapses, and the maximum collapse span reaches $20 \mathrm{~m}$, resulting in a minimum distance of $25 \mathrm{~m}$ from the main shaft and auxiliary shaft to the collapsed area. The large-scale collapses of the main ore pass have seriously affected its own use and threatened the normal use of the main shaft and auxiliary shaft.

2.2. Special Requirements to Plug the Main Ore Pass. Due to the mine production needs, the production level needs to be transferred from $-180 \mathrm{~m}$ to $-330 \mathrm{~m}$; it means that the section of the main ore pass below $-330 \mathrm{~m}$ still needs to be used. Therefore, it is necessary to quickly plug the main ore pass above $-330 \mathrm{~m}$. Due to the serious collapse of the main ore pass, the plugging scheme under conventional empty condition is likely to have a fatal impact on the stability of the nearby shaft and station, and the risk of construction operation in the ore pass is too great. In addition, the construction period is too long to cause a large economic loss for a mine that is in production. Therefore, there is only one option to plug the main ore pass with large collapses, that is, under the condition that the ore pass is full of waste rock and the personnel do not enter the ore pass; the main ore pass is realized quickly in $-330 \mathrm{~m}$.

This approach faces three key issues:

(a) Constructing the plugging structure under the condition of filling the ore pass can ensure the stability of the plugging structure itself

(b) The construction of the nonentry plugging structure is based on grouting to the loose rock mass, and the grout cannot block the lower section of the ore pass and the inclined drift in the level of $-330 \mathrm{~m}$; that is, the grout diffusion must be controlled in the vertical direction. Controllable grouting is also the core of this project 

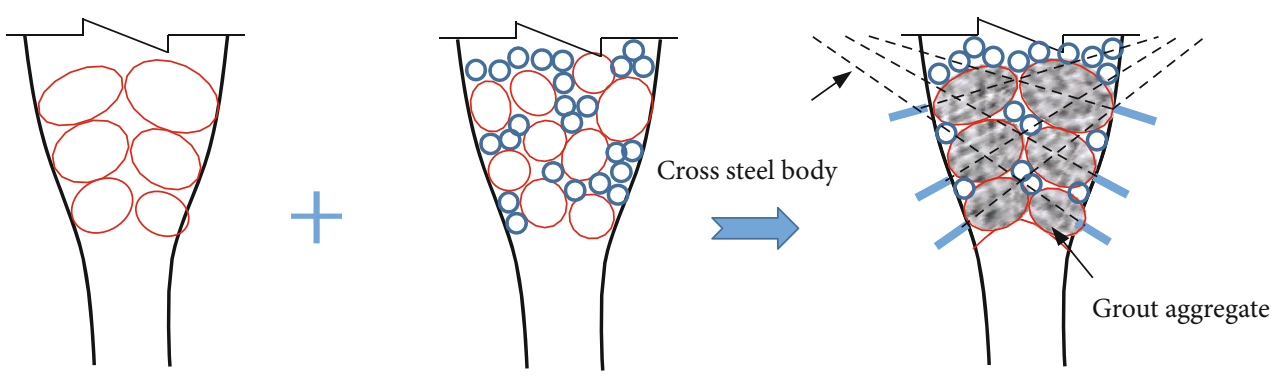

Figure 2: Main idea of the plugging design of the main ore pass: (a) occlusal arch; (b) cohesive arch; (c) artificial bite-bonded arch.

(c) The influence of the constructed plugging structure is on the stability of the main shaft and auxiliary shaft

2.3. Design Idea to Plug the Main Ore Pass. In order to answer the above three key questions, the analysis is based on design ideas and technical measurements are decomposed step by step as follows:

(a) The plugging mode of the ore pass is inspired by the phenomenon of overhanging arches frequently occurring in ore passes $[2,3]$, and the occlusal arch and cohesive arch in the overhang arch are fully combined to form a stable plugging structure by constructing a "bite-bonded arch," which is formed by methods of grouting and installing a cross steel body in the loose rock mass, as shown in Figure 2

(b) Based on the characteristics of large voids in the loose rock mass, it is difficult to control the diffusion range of cement grout in the loose rock mass. Therefore, cement-silicate grout is used to expect controllable diffusion in the loose rock mass based on its viscosity-time-denatured characteristic. But the diffusion distance, especially the vertical diffusion distance, is still a problem to be solved, which will be discussed below

(c) Numerical modelling is used to fully evaluate the influence of the scheme for the surrounding main shaft and auxiliary shaft

\section{Controllable Grouting of Cement-Silicate Grout in the Loose Rock Mass}

3.1. Viscosity Time-Varying Characteristic of Cement-Silicate Grout. During the plugging project of the main ore pass, the cement-silicate grout infusion in the loose rock mass must be vertically controllable, that is, the coupling effect in the vertical flow between the grout of viscosity time-varying and the loose rock mass with a large void. This problem belongs to the one-dimensional seepage of typical unsteady fluids, and the solution is more complicated. Based on plugging engineering requirements of the main ore pass, this problem is simplified and solved in view of engineering.

First of all, it is necessary to clarify the general law of viscosity time-varying characteristic for cement-silicate grout.
The Brookfield's new R/S+ rheometer was used to carry out the viscosity time-varying test of two-proportion grout. It was found that the viscosity of the cement-silicate grout showed a power function change with time, as shown in Figure 3. This is consistent with the findings of relevant scholars like Liu [22].

By fitting the two-proportion grout, the following formula can be used uniformly:

$$
\mu(t)=A e^{a t}
$$

where $A$ and $a$ are constants related to the viscosity of the cement-silicate grout, which can be obtained by fitting the experimental data. It shows that the viscosity of the cement-silicate grout of a specific ratio is only a function related to $t$, and the function can be divided into two stages: the grout viscosity is close to 0 and the viscosity of the grout rapidly climbed in a short period of time.

3.2. Scientific Conception of Controllable Grouting of CementSilicate Grout in the Loose Rock Mass. Combined with the specific engineering needs that vertical flow of cementsilicate grout cannot block the lower section of the ore pass, in view of practical technology, it is assumed that the onedimensional vertical diffusion distance of cement-silicate grout with different setting times in the specific loose rock mass is also expressed as a function only related to the setting time. For this reason, some data of one-dimensional vertical seepage diffusion from the heap grouting test (Figure 4(a)) and the plugging engineering application (Figure 4(b)) are fitted, and the curve is shown in Figure 4(c). The specific expression is as follows:

$$
H(t)=B e^{b t},
$$

where $H(t)$ is the vertical diffusion distance of the cementsilicate grout in the loose rock mass $(\mathrm{m}), t$ is the setting time of the grout, and $B$ and $b$ are the constants related to the setting time of cement-silicate grout and the loose rock mass. These are fitted from the heap grouting test.

It shows that the vertical diffusion distance of the cement-silicate grout in the loose rock mass can also be fitted to the power function, and the correlation is good, which is also consistent with the scientific assumption above.

For the specific loose rock mass, the correlation between the one-dimensional vertical diffusion distance of the cement-silicate grout and the setting time of grout can be 


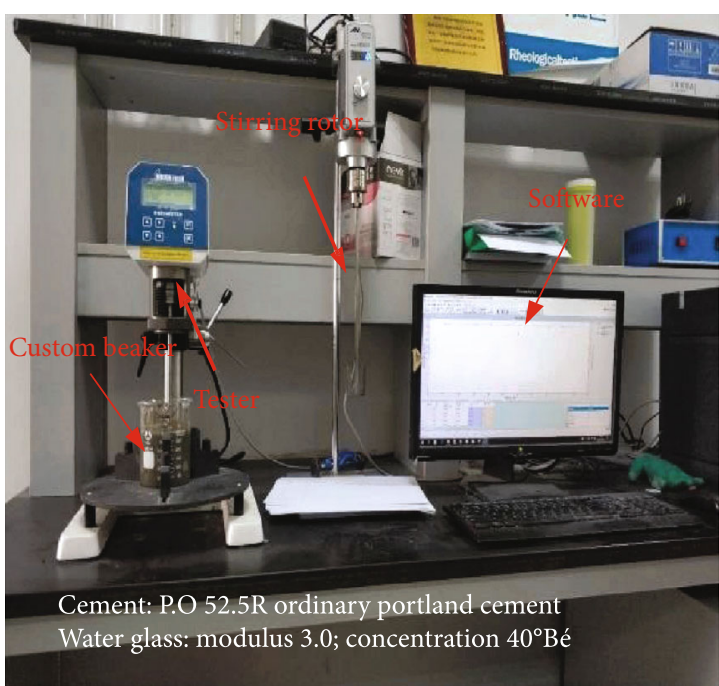

(a) Brookfield new R/S+ rheometer

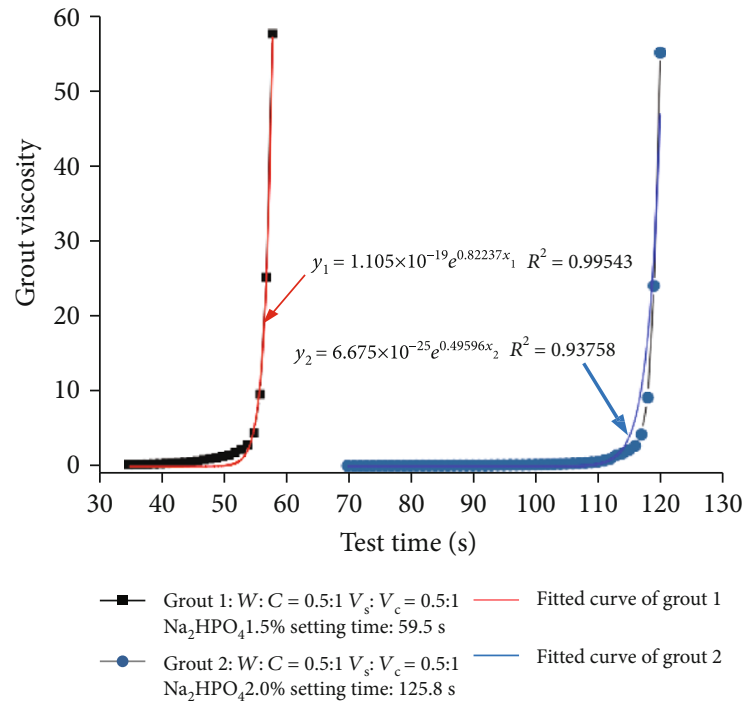

(b) The curve of grout viscosity with time

FIGURE 3: Determination and viscosity characteristics of cement-sodium silicate grout.

achieved by fitting the multiple data from heap grouting tests. The vertical diffusion distance of the cement-silicate grout in the loose rock mass is predicted to determine the required grout setting time and grout proportion in the reverse direction, so as to realize the controllable diffusion of cementsilicate grout in the large scale of the loose rock mass.

This kind of solution method based on engineering needs can fully meet the accuracy requirements of engineering technology.

\section{Design and Application of the Plugging Scheme}

Based on the design idea of the main ore pass plugging, a man-made "bite-bonded arch" was constructed. The specific plugging design and construction process flow are shown in Figure 5.

Step 1. With the emptying of ores in the lower ore mass, gradually pour $2800 \mathrm{~m}^{3}$ of $4 \mathrm{~cm} \sim 6 \mathrm{~cm}$ gravels from the level of $-180 \mathrm{~m}$ to replace ores in the plugging area, so as to avoid extreme condition that the large-diameter stone cannot be passed by casing. So the construction efficiency and grouting effect can be ensured.

Step 2. Consider the vertical controllable grouting results and the grouting effect in the horizontal direction, 6 rows of casing pipes are arranged on the side of the measure chamber, wherein the row spacing between the first row and second row is $0.5 \mathrm{~m}$. The row spacing between the $3 \mathrm{rd}$ and 5 th rows is $0.8 \mathrm{~m}$, the spacing is $1.0 \mathrm{~m}$, and the lower cross-control pipe spacing is $1.0 \mathrm{~m}$. The 3 rows of casing pipes are arranged on the side of the linking drift to the main ore pass, and the spac- ing is $2.0 \mathrm{~m}$. Firstly, pipes located in the measure chamber are constructed, and pipes located in the linking drift to the main ore pass are followed, which is shown in Figure 6.

Step 3. Six $\varphi 15.24 \mathrm{~mm}$ cables are interspersed in the every pipe, and six cables are bundled to form a prestressed cable bundle. Finally, a diagonally inclined structure is formed on both sides of the main ore pass. The design length of the anchoring section is $7 \sim 8 \mathrm{~m}$.

Step 4. In order to control the vertical diffusion distance, based on the results of the heap grouting test, the setting time of cement-silicate grout is $140 \mathrm{~s}$ and $200 \mathrm{~s}$, and the vertical maximum diffusion length of the grout is $7.2 \mathrm{~m}$ and $15.7 \mathrm{~m}$, respectively. The vertical flows stop automatically when they flow to the lower mouth of the inclined drift, and the grout diffusion range just meets the engineering design requirements. In order to control the grouting effect, the overflow hole arrangement located in the casing pipe body is also optimized. An overflow hole is arranged at a distance of $30 \mathrm{~cm}$ along the pipe body, and the plume-shaped arrangement is applied in the longitudinal direction.

The appropriate spacing between the casings is designed, and 81 pipes are used during the engineering. Due to the controllable grouting of the cement-silicate grout in the loose rock mass, the voids in the loose rock mass may not be completely filled with the grout, and somewhere is empty. Therefore, the stone body of cement-sodium silicate grout in the loose rock mass is multiple aggregates bonded by the grout and loose rock mass. The formed aggregates are interspersed together by prestressed cables, which finally constitute about 27 aggregates. These aggregates bite and bond together to form a plugging structure for the main ore pass with large collapses. 


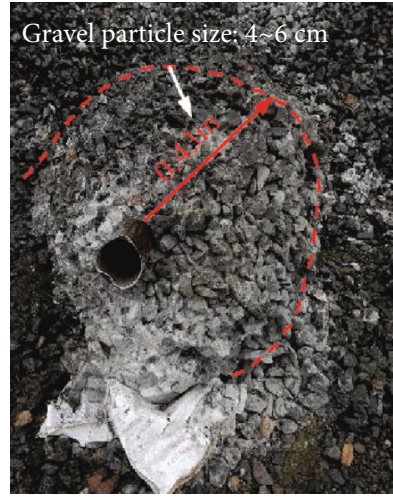

(a) Heap grouting test

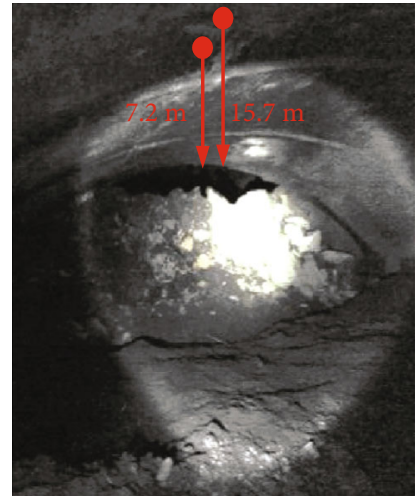

(b) Grouting measurement in the on-site construction

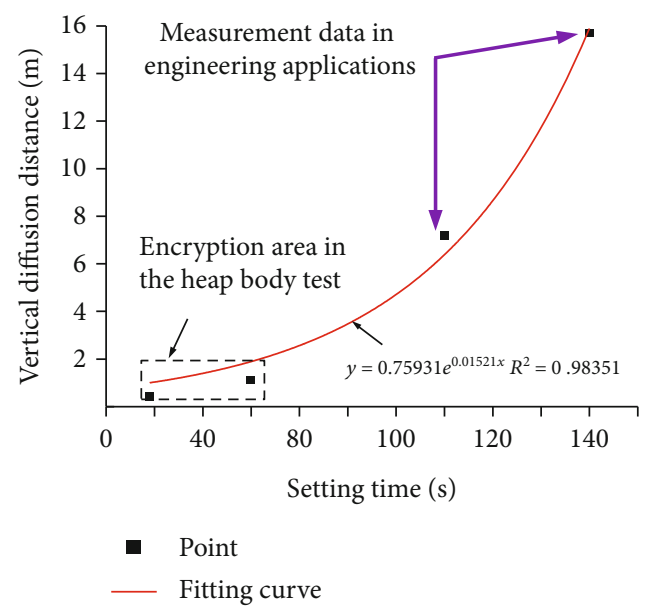

(c) Vertical diffusion distance of grout in the loose rock mass

FIGURE 4: Realization of controllable grouting of cement-silicate grout in the loose rock mass.

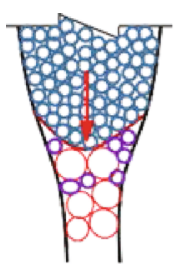

Step 1

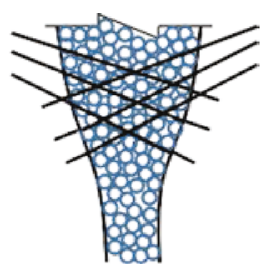

Step 2

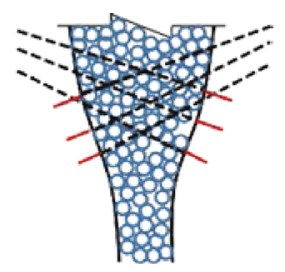

Step 3

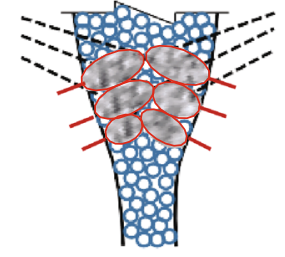

Step 4

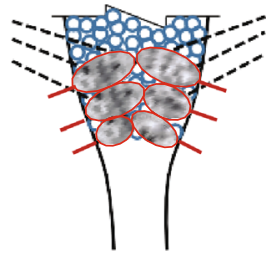

Step 5

Figure 5: Plugging design and construction process flow of the main ore pass.

Step 5. After the grouting body has been cured for 7 days, the prestressed cables are tensioned to a design value of $600 \mathrm{kN}$. Then, the rocks in the lower section of the ore pass are emptied, and the function of using the lower section of the main ore pass is completely restored.

\section{Stability Evaluation}

In order to evaluate the stability of the plugging structure, numerical modelling of the stability of the plugging structure is carried out. In addition, the stress of cables at the typical areas of the plugging structure is monitored for a long time.

\subsection{Numerical Modelling}

5.1.1. Engineering Mechanics Model. The engineering geomechanics model based on the main ore pass with large collapses is shown in Figure 7. The model with size of $190 \mathrm{~m} \times 190 \mathrm{~m} \times 250 \mathrm{~m}$ is given, including key projects such as the main ore pass, main shaft, auxiliary shaft, measure chamber, and linking drift to the main shaft from $-180 \mathrm{~m}$ to $-360 \mathrm{~m}$. The model has a total of 291,069 zone elements and 156,507 nodes, and physical and mechanical parameters of zone elements are shown in Table 1 from Wang [23] and Yu et al. [24]. Among them, after fully considering the filling degree of the stone body of the cement-silicate grout, the 


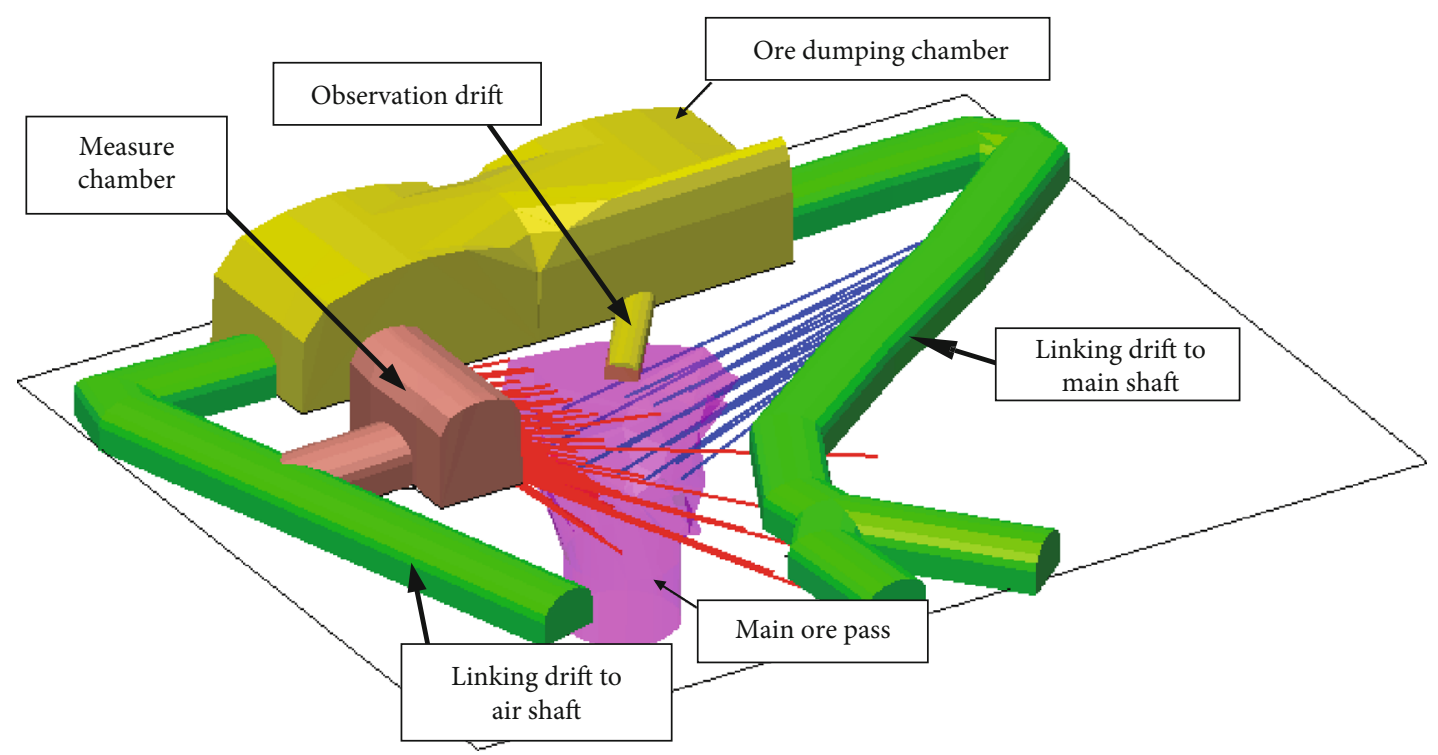

FIGURE 6: Design and construction of controllable grouting in the plugging project.

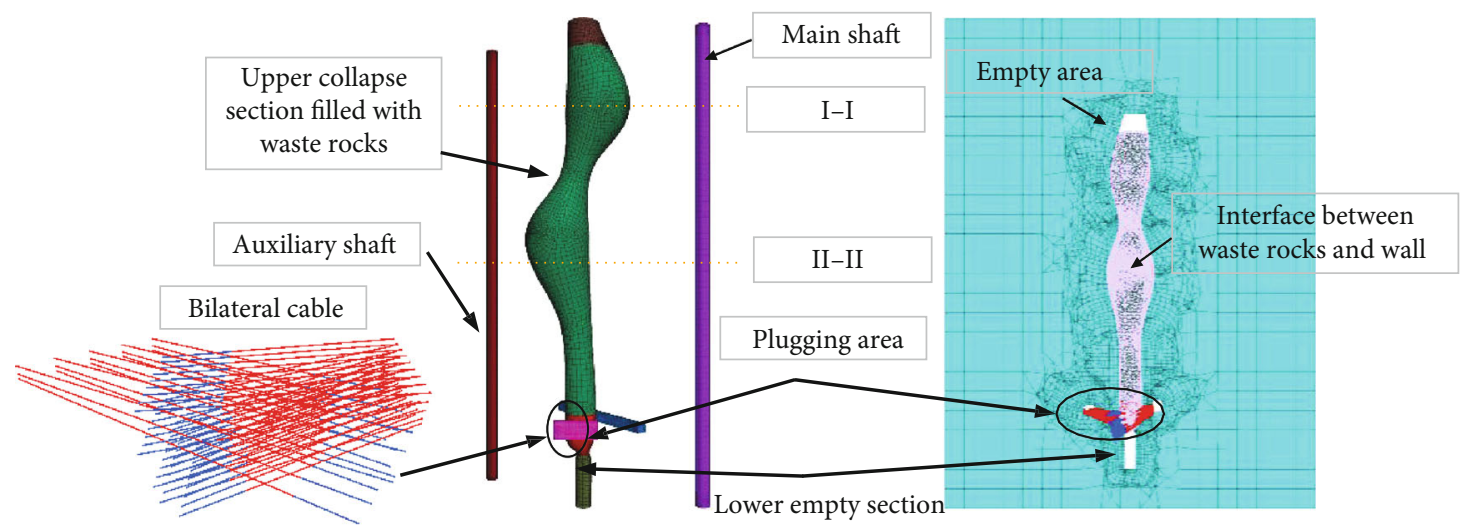

FIGURE 7: Engineering geomechanics model.

physical and mechanical parameters of the stone body are comprehensively evaluated. The failure criterion is MohrCoulomb. In the simulation, the cable is made of cable elements, and the interfaces between the inner filling and the wall of the ore pass are made of interface elements. The formula to calculate the normal stiffness and shear stiffness of different interfaces is as follows:

$$
k_{\mathrm{n}}=k_{\mathrm{s}}=10 \times \max \left(\frac{(J+4 G) / 3}{\Delta Z_{\min }}\right) \text {, }
$$

where $J$ is the bulk modulus of the filling in the ore pass, $G$ is the shear modulus of the filling in the ore pass, and $\Delta Z_{\min }$ is the minimum grid size of zones between the filling and the surrounding rocks.

The mechanical parameters of the interface are calculated according to the above formula and shown in Table 2, and the shear strength parameters of gravels are mainly based on the suggested values given in Wang [23]. In addition, the deformation parameter and density are used according to the filling time in the long-term situation given in Xie et al. [25]:

$$
\begin{gathered}
\rho=1600+800\left(1-e^{-1.25 t}\right), \\
E=15+175\left(1-e^{-1.25 t}\right), \\
\mu=0.05+0.2\left(1-e^{-1.25 t}\right),
\end{gathered}
$$

where $t$ is the time (a), $\rho$ is the density of gravels $\left(\mathrm{kg} / \mathrm{m}^{3}\right), E$ is the elastic modulus of gravels ( $\mathrm{MPa})$, and $\mu$ is Poisson's ratio of gravels.

5.1.2. Simulation Scheme. In order to evaluate the stability of the main ore pass, main shaft, and auxiliary shaft before and after the plugging, three conditions were simulated as follows:

(a) Plugging: the above plugging design scheme is adopted, and the lower section of the main ore pass is emptied

(b) Emptying: the main ore pass is completely emptied 
TABLE 1: The physical and mechanical parameters to be used.

\begin{tabular}{lcccccc}
\hline Rock mass & $\begin{array}{c}\text { Density }\left(\mathrm{kg} \cdot \mathrm{m}^{-}\right. \\
\left.{ }^{-}\right)\end{array}$ & $\begin{array}{c}\text { Elastic modulus } \\
(\mathrm{GPa})\end{array}$ & $\begin{array}{c}\text { Poisson } \\
\text { ratio }\end{array}$ & $\begin{array}{c}\text { Friction angle } \\
\left.{ }^{\circ}\right)\end{array}$ & $\begin{array}{c}\text { Cohesive force } \\
(\mathrm{MPa})\end{array}$ & $\begin{array}{c}\text { Tension strength } \\
(\mathrm{MPa})\end{array}$ \\
\hline $\begin{array}{l}\text { Surrounding rocks } \\
\begin{array}{l}\text { Replacement of } \\
\text { gravels }\end{array}\end{array}$ & 2660 & 5.16 & 0.25 & 42.7 & 1.93 & 0.29 \\
\begin{tabular}{l} 
Grouting stone body \\
\hline
\end{tabular} & 2400 & 0.19 & 0.25 & 40.5 & 0 & 0 \\
\end{tabular}

TABLE 2: The mechanical parameters of interfaces.

\begin{tabular}{lcccc}
\hline Interface & $\begin{array}{c}\text { Normal stiffness } k_{\mathrm{n}}\left(\mathrm{GPa} \cdot \mathrm{m}^{-}\right. \\
\left.{ }^{1}\right)\end{array}$ & $\begin{array}{c}\text { Shear stiffness } k_{\mathrm{s}}\left(\mathrm{GPa} \cdot \mathrm{m}^{-}\right. \\
\left.{ }^{-}\right)\end{array}$ & $\begin{array}{c}\text { Poisson's ratio } \\
\left({ }^{\circ}\right)\end{array}$ & $\begin{array}{c}\text { Cohesive force } \\
(\mathrm{MPa})\end{array}$ \\
\hline $\begin{array}{l}\text { Surrounding rock and gravel } \\
\begin{array}{l}\text { Surrounding rock and grouting } \\
\text { gravel }\end{array}\end{array}$ & 8.52 & 8.52 & 33.5 & 0 \\
\hline
\end{tabular}

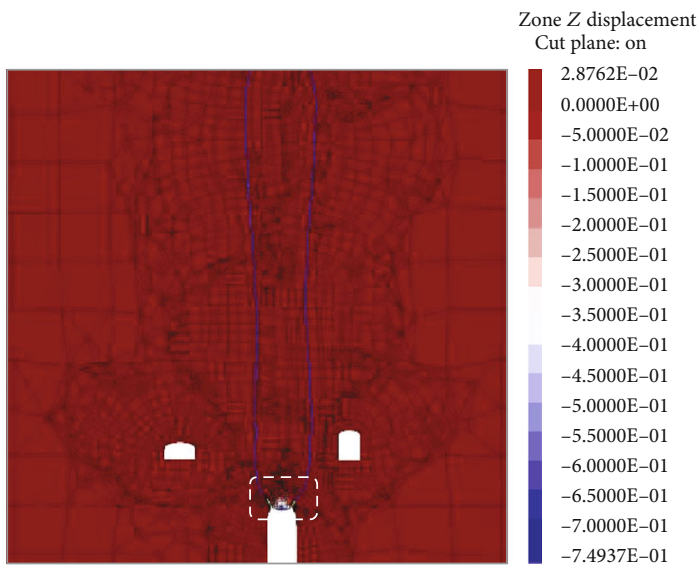

(a) Plugging

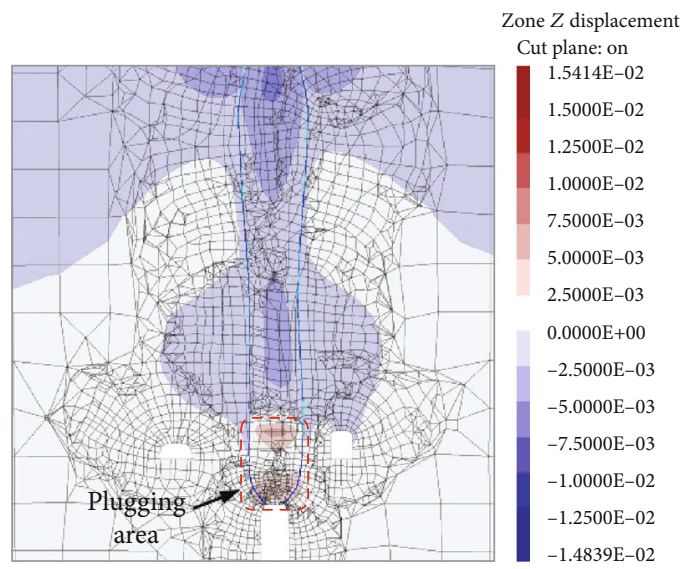

(b) Nonplugging

FIgURE 8: Vertical deformation distribution diagram of the plugging area.

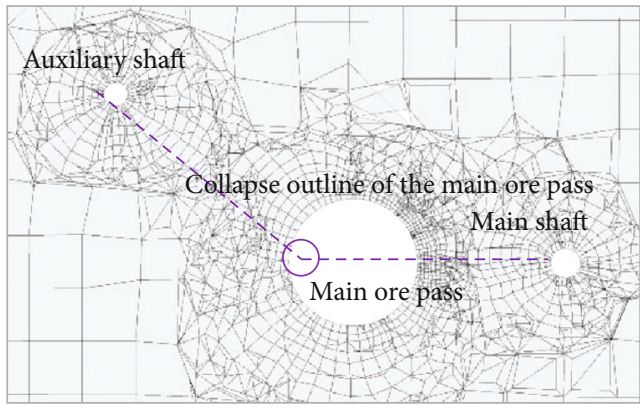

(a) I-I

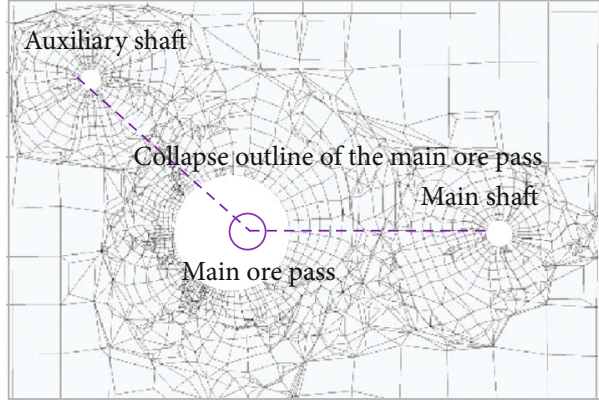

(b) II-II

FIgURE 9: The maximum collapse section to be analyzed.

(c) Nonplugging condition: the lower section of the main ore pass is emptied, but the upper section is still filled with waste rocks
5.1.3. Stability Evaluation of the Plugging Structure Itself. In order to fully illustrate the self-stability of the designed plugging structure, a typical vertical section is selected for 


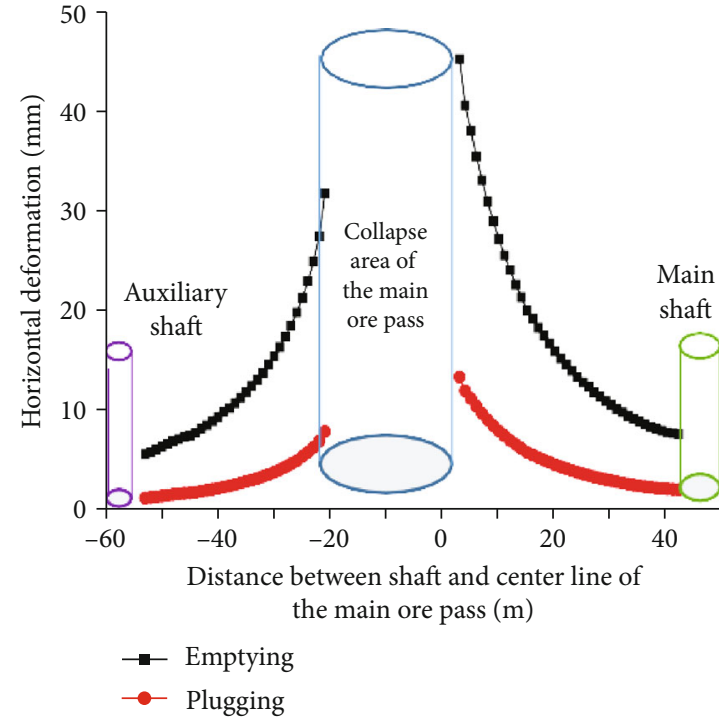

(a) I-I

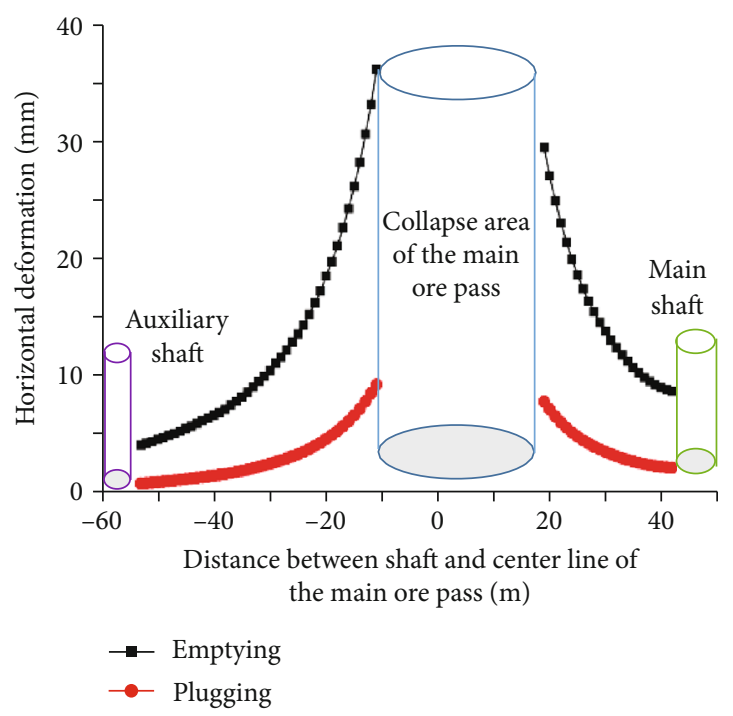

(b) II-II

FIGURE 10: Effect of the plugging structure on the movement and deformation of the main shaft and auxiliary shaft nearby.

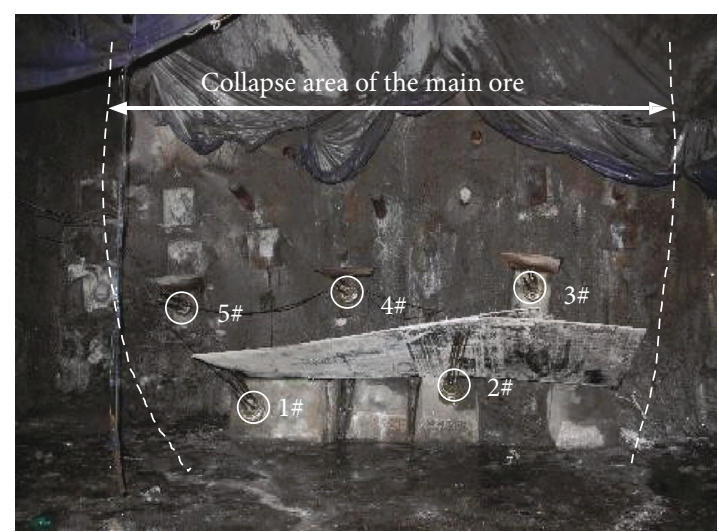

(a) Installation position of monitoring cables

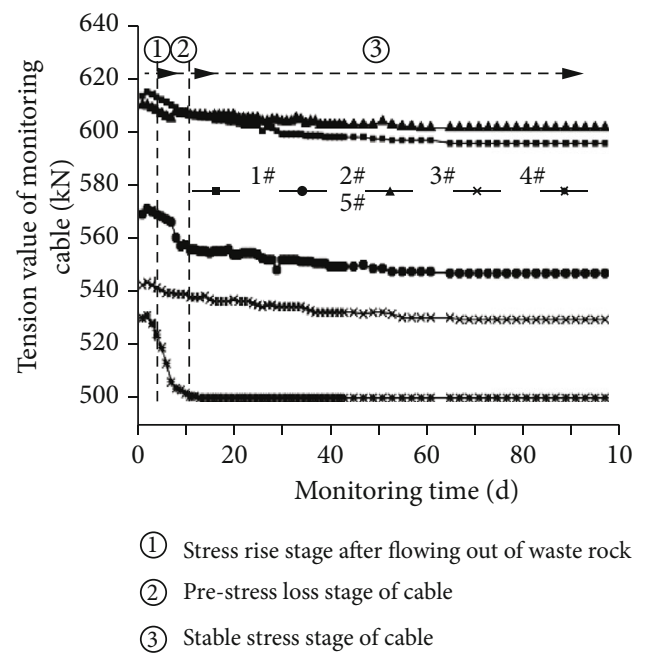

(b) Tension curve of monitoring cables

FIGURE 11: The layout of cable sensors and its long-term monitoring curve.

comparative analysis between the condition of plugging and the condition of nonplugging as shown in Figure 8. In the nonplugging condition, after the waste rock in the lower section is emptied, the same time step is calculated and the vertical deformation of the bottom reaches $74.9 \mathrm{~cm}$; that is, the friction between the waste rocks and the side wall cannot prevent the vertical movement of the waste rocks in the upper section. In the plugging condition, after the plugging is finished and the waste rocks in the lower section are emptied, the same time step is calculated and the maximum vertical deformation amount at the bottom of the plugging area is $0.25 \mathrm{~cm}$.
The overall deformation of the plugging structure is small, indicating that the downward movement deformation of the plugging structure is effectively controlled by using the plugging design, and the plugging structure is at a stable state.

5.1.4. Influence of the Plugging Structure on the Main Shaft and Auxiliary Shaft. In order to fully explain the control effect of the designed plugged structure on the movement of the nearby main shaft and auxiliary shaft, the two typical horizontal sections in Figure 9 were selected for comparative analysis of the condition of emptying and the condition of plugging; analysis results are shown in Figure 10. It can be 
seen that in the empty state, the displacement of the main shaft and the auxiliary shaft caused by the large collapse of the main ore pass is about $5 \mathrm{~mm}$, which may cause the deformation of the main shaft and auxiliary shaft at these positions. In the case of the plugging condition, since the entire collapsed area of the main ore pass is filled with the waste rocks, the deformation of the main shaft and auxiliary shaft is small, and the stability of the main shaft and auxiliary shaft is not affected. Therefore, the designed plugging structure can meet the requirements for maintaining the stability of the main shaft and auxiliary shaft nearby.

5.2. Analysis of Monitoring Results. In order to truly reflect the stable state of the main ore pass after repair, since other measuring devices cannot be directly installed on the plugging structure, a high-precision cable sensor that can reflect indirectly the stability of the plugging structure is preferred, and it is installed on the cable bundle for continuous monitoring, as shown in Figure 11(a).

Among them, 1\# 4\# monitoring points are installed at the core of the collapse area of the main ore pass, and $5 \#$ is located at the edge.

According to the monitoring results in Figure 11(b), the monitoring data of the five sensors tend to be stable after the short-term adjustment, so the "bite-bonded arch" which is based on the controllable grouting of the cement-silicate grout in the loose rock mass is reasonable and reliable in structure. It shows that the controllable grouting of cementsilicate grout in the loose rock mass has been successfully applied in the plugging project of the ore pass with the large collapse.

\section{Conclusion}

In this paper, the controllable grouting technology of the cement-silicate grout in the loose rock mass is proposed. Based on the technology, combined with the actual situation of the plugging of the main ore pass at Xingshan Iron Mine, a man-made "bite-bonded arch" based on the plugging design concept is proposed, and related engineering is carried out. The stability of the plugging structure is comprehensively evaluated by numerical modelling and long-term monitoring of cable stress. The conclusions are as follows:

For the specific loose rock mass, the correlation between the one-dimensional vertical diffusion distance of the cement-silicate grout and the setting time of grout can be achieved by fitting the multiple data from heap grouting tests. The vertical diffusion distance of the cement-silicate grout in the loose rock mass is predicted to determine the required grout setting time and grout proportion in the reverse direction, so as to realize the controllable diffusion of cementsilicate grout in the large scale of the loose rock mass.

Based on the design concept of constructing a man-made "bite-bonded arch" in the main ore pass with the large collapse, a 5-step main ore pass design and construction process flow are proposed with multiple grouting aggregates as the core.

Based on the results of numerical modelling and longterm monitoring of cable stress, the plugging structure is sta- ble and the plugging scheme is effective to control the movement deformation of the main shaft and auxiliary shaft nearby.

\section{Data Availability}

The data used to support the findings of this study are included within the article.

\section{Conflicts of Interest}

The authors declare that they have no conflicts of interest.

\section{Acknowledgments}

This work was supported by the National Natural Science Foundation of China under Grant numbers 41602365 and 51674265 .

\section{References}

[1] H. Chen, S. Yu, Z. Wang, and Y. Yuan, "A new plugging technology and its application for the extensively collapsed ore pass in the non-empty condition," Energies, vol. 11, no. 6, p. 1599, 2018.

[2] Z. X. Lu, Z. Q. Zhang, and G. J. Zhang, "Mechanism of hanging-up phenomena and its solving countermeasures in transportation of ore pass," China Mining Magazine, vol. 26, no. 4, pp. 153-157, 2017.

[3] Z. X. Lu, C. Ma, and Y. Yin, "Mechanism of deformation and failure on ore pass wall under impact and wear," Metal Mine, vol. 11, pp. 37-40, 2018.

[4] S. B. Yu, H. Chen, H. Cao, Y. Yuan, J. Z. Zhao, and C. Guo, "Analysis and engineering application of blocking pressure of ore-pass," China Mining Magazine, vol. 25, Supplement 2, pp. 299-302, 2016.

[5] Y. Li, S. Zhang, and X. Zhang, "Classification and fractal characteristics of coal rock fragments under uniaxial cyclic loading conditions," Arabian Journal of Geosciences, vol. 11, no. 9, p. 201, 2018.

[6] G. Shi, X. Yang, H. Yu, and C. Zhu, "Acoustic emission characteristics of creep fracture evolution in double-fracture fine sandstone under uniaxial compression," Engineering Fracture Mechanics, vol. 210, pp. 13-28, 2019.

[7] Z. Qin, H. Fu, and X. Chen, "A study on altered granite mesodamage mechanisms due to water invasion-water loss cycles," Environmental Earth Sciences, vol. 78, no. 14, p. 428, 2019.

[8] H. Kim and C. Jang, "Vertical suspended sediment diffusivity for uniform currents," KSCE Journal of Civil Engineering, vol. 17, no. 6, pp. 1496-1501, 2013.

[9] Y. Li, R. Huang, L. S. Chan, and J. Chen, "Effects of particle shape on shear strength of clay-gravel mixture," KSCE Journal of Civil Engineering, vol. 17, no. 4, pp. 712-717, 2013.

[10] J. Hadjigeorgiou and J. F. Lessard, "Strategies for restoring material flow in ore and waste pass systems," International Journal of Mining, Reclamation and Environment, vol. 24, no. 3, pp. 267-282, 2010.

[11] J. Hadjigeorgiou and J. F. Lessard, "Numerical investigations of ore pass hang-up phenomena," International Journal of Rock Mechanics and Mining Sciences, vol. 44, no. 6, pp. 820-834, 2007. 
[12] T. Vo, H. Yang, and A. R. Russell, "Cohesion and suction induced hang-up in ore passes," International Journal of Rock Mechanics and Mining Sciences, vol. 87, pp. 113-128, 2016.

[13] T. Szwedzicki, "Formation and removal of hang-ups in ore passes," Mining Technology, vol. 116, no. 3, pp. 139-145, 2013.

[14] Z. X. Kuang and W. D. Song, "Numerical analysis of the interaction mechanism of no. 1 and no.2 main shafts at Chengchao iron mine," Metal Mine, vol. 7, pp. 9-11, 2002.

[15] K. Esmaieli, J. Hadjigeorgiou, and M. Grenon, "Stability analysis of the 19A ore pass at Brunswick mine using a two-stage numerical modeling approach," Rock Mechanics and Rock Engineering, vol. 46, no. 6, pp. 1323-1338, 2013.

[16] C. H. Li, M. F. Cai, L. Qiao et al., "Engineering design and construction effect of reinforcement measures of main ore-pass," Mine Construction Technology, vol. 3, pp. 21-23, 1999.

[17] Z. Li, H. Liu, Z. Dun, L. Ren, and J. Fang, "Grouting effect on rock fracture using shear and seepage assessment," Construction and Building Materials, vol. 242, article 118131, 2020.

[18] Z. Li, H. Zhou, D. Hu, and C. Zhang, "Yield criterion for rocklike geomaterials based on strain energy and CMP model," International Journal of Geomechanics, vol. 20, no. 3, article 04020013, 2020.

[19] Z. Li, S. Liu, W. Ren, J. Fang, Q. Zhu, and Z. Dun, "Multiscale laboratory study and numerical analysis of water-weakening effect on shale," Advances in Materials Science and Engineering, vol. 2020, Article ID 5263431, 14 pages, 2020.

[20] X. Wang, C. Liu, S. Chen, L. Chen, K. Li, and N. Liu, "Impact of coal sector's de-capacity policy on coal price," Applied Energy, vol. 265, p. 114802, 2020.

[21] Q. Meng, H. Wang, M. Cai, W. Xu, X. Zhuang, and T. Rabczuk, "Three-dimensional mesoscale computational modeling of soil-rock mixtures with concave particles," Engineering Geology, vol. 277, article 105802, 2020.

[22] R. T. Liu, Study on diffusion and plugging mechanism of quick setting cement based slurry in underground of dynamic water grouting and its application, [Ph.D. thesis], Shandong University, Jinan, China, 2012.

[23] Y. M. Wang, Modern Mining Manual, Metallurgical Industry Press, Beijing, China, 2012.

[24] S. B. Yu, Y. Yuan, and H. Wang, Research on a Key Technique of Pluging of Main Ore-Pass Shaft in Xingshan Irion Mine, Being General Research Institue of Mining \& Metallurgy, Beijing, China, 2015.

[25] H. P. Xie, H. W. Zhou, J. A. Wang, L. Z. Li, and M. A. Kwasniewski, "Application of FLAC to predict ground surface displacements due to coal extraction and its comparative analysis," Chinese Journal of Rock Mechanics and Engineering, vol. 18, no. 4, pp. 397-401, 1999. 